\title{
Allan MacLeod Cormack (1924-1998): Discoverer of computerised axial tomography
}

\author{
Siang Yong $\underline{\operatorname{Tan}^{1}}, \mathrm{MD}, \mathrm{JD}$, Patricia Sims $\underline{\text { Poole }^{2}}$
}

It is not much of an exaggeration to say that what (Godfrey) Hounsfield and I know about medicine and physiology could be written on a small prescription form.

- Allan Cormack, in his Nobel address

$\mathrm{F}$ rom historical times, human senses such as touch, smell and sight have served as the physician's primary tools in physical diagnosis. Evolution of medicine, in a real sense, has meant the evolutionary refinement of these senses, such as enhancing hearing with the stethoscope or ultrasonography. Preeminent among the items we have refined is visual augmentation to enable us to see things that are normally hidden from view. To peer beyond the skin, early vivisectionists, culminating in Dr Andreas Vesalius in the 16th century, took to daring dissections to study human body components. In the present day, student doctors study the location and structure of tissues and organs in freshman anatomy classes, then go on to analyse surgical specimens and autopsies in pathology classes.

Wilhelm Roentgen's discovery of X-rays in 1895, for which he won the Nobel Prize in Physiology or Medicine in 1901, provided the breakthrough for overcoming the superficiality of sight and allowed the physician to literally view the 'insides' of a living patient. This pioneering diagnostic marvel has held its revered position ever since, despite its inability to show internal structures in three dimensions, especially of soft tissues. For example, a physician can see the outlines of a tumour or

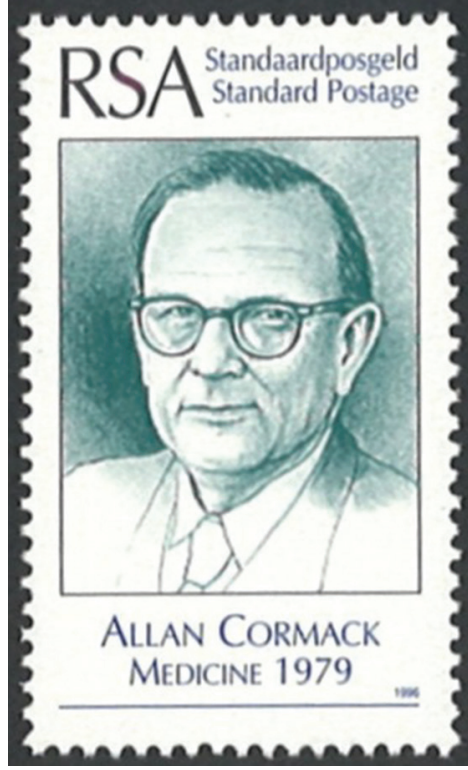

MacLeod, and father, George Cormack. His mother was a teacher and his father an engineer, and they had immigrated to South Africa just before World War I. They eventually settled in Cape Town, where Cormack attended Rondebosch Boys' High School and showed early promise in tennis, debating and astronomy. His spare time was spent mountaineering in the ranges of the Western Cape province or Table Mountain in his back yard. In astronomy, he is said to have devoured the popular works of Sir Arthur Eddington and Sir James Jeans, British astrophysicists. In his autobiography, he credits his fondness for mathematics and physics to these authors. They must have been the inspiration that spurred his career in physics and his subsequent discovery of CT.

After completing high school, Cormack attended the University of Cape Town. Like his father and brother, he pursued studies in electrical engineering but switched to physics after a couple of years, completing his Bachelor of Science in 1944 and his Master of Science with specialisation in crystallography the following year. Cormack then moved to the Cavendish Laboratory at St John's College, Cambridge, United Kingdom, as a research student, working under Professor Otto Frisch from 1947 to 1949. There, he met an American woman, his future wife Barbara Seavey, purportedly during one of Nobel physicist Paul Dirac's lectures on quantum mechanics. He proposed marriage but was broke, so moving back to the physics department at Cape Town was necessary to secure himself both a job and a bride. However, this came with a sacrifice, the distorted ball joint of the skeleton, but the inability to view the structure in three dimensions limits the full appreciation of pathology.

THE MAN WITH THE SOLUTION Computerised axial tomography (CAT), the ubiquitous CAT or computed tomography (CT) scan, was a landmark discovery that allowed clinicians to view the interior of the human body in three dimensions without using invasive means. The man with the solution was Allan MacLeod Cormack, a physicist with neither a Doctor of Philosophy nor Doctor of Medicine, who deservedly shared the 1979 Nobel Prize for Physiology or Medicine for his discovery of CT. Cormack was born in Johannesburg, South Africa, on 23 February 1924, to a Scottish mother, Amelia as his new position lacked a cyclotron for his research work. His stint at the University of Cape Town from 1950 to 1956 was a rather lonely one, as there were very few nuclear physicists in South Africa at that time, the nearest being more than $900 \mathrm{~km}$ away. Still, he was productive, and his students, especially the undergraduates, were inspired by his lectures.

FROM PHYSICS TO RADIOLOGY In early 1956, Cormack served as resident medical physicist in the radiology department at Cape Town's Groote Schuur Hospital, the chief academic hospital of the University of South Africa's medical school. It later became famous for the first human heart transplant, performed there by Dr Christiaan Barnard. Cormack, the only available trained nuclear physicist, supervised the use

${ }^{1}$ Emeritus Professor of Medicine, University of Hawaii, ${ }^{2}$ Research carried out during transitional residency, University of Hawaii, Honolulu, USA

Correspondence: Prof Tan Siang Yong, 2226 Liliha Street, Suite B-104, Honolulu, HI 96817, USA. siang@hawaii.edu 
of radioisotopes as well as the calibration of film badges used to monitor hospital workers' exposure to radiation. He also witnessed how radiation was used in the diagnosis and treatment of cancer. While Cormack's primary interest was particle physics, he became fascinated by imaging technology and its deficiencies, and began a series of experiments towards constructing a radiological crosssectional view of biological systems. This resulted in two basic science papers published separately between 1963 and 1964 in the Journal of Applied Physics, which formed the foundational theoretical basis for CT scanning. Unfortunately, they generated almost no interest from the scientific community at the time despite the potential of revealing previously unviewable or just barely viewable cross-sections of the body in vivo.

Cormack's work was interrupted by a sabbatical at Harvard University, Cambridge, Massachusetts, United States, in 1956-1957. In his autobiography, he wrote that as his wife had come to the wilds of Africa with him, it was only reasonable that he should go to the wilds of America with her on his first sabbatical. Also, Harvard had a cyclotron laboratory, which had been used almost exclusively for physics research before 1961. Allan joined the faculty of Tufts University in Boston as an assistant professor and in 1966 became a naturalised citizen of the United States. His main departmental interests were in the study and teaching of nuclear and particle physics. Between 1956 and 1964, he conducted most of his research on the development of CAT in his own time, but his studies became inactive due to his colleagues' lack of interest in his work. However, in the period of 1970-1972, interest in imaging techniques increased, and his enthusiasm was rekindled. It culminated in his discovery of CT and eventual winning and sharing of the Medicine/Physiology Nobel Prize with Sir Godfrey Newbold Hounsfield, who invented a quantitative scale for describing radiodensity.

CAT SCAN CT utilises serial recordings of cross-sectional radiographic images to produce computer-processed composites of a scanned object. Digital geometry processing is then used to further generate a three-dimensional volume of the inside of the object. The term CT is often used to refer to X-ray CT, because it is the most commonly known form. But other types of CT exist, such as PET (positron emission tomography) and SPECT (singlephoton emission computed tomography) imaging. In 2015, more than 80 million CT procedures were performed in the United States, and concerns of malignancies stemming from CT radiation exposure remain unconfirmed. Although most commonly used in medicine, CT is also used in non-medical fields such as for materials testing and imaging the contents of archaeological specimens, sarcophagi or ceramics.

\section{OTHER HONOURS AND AWARDS At Tufts,} Cormack progressed up the academic ladder at the physics department to become an associate and then a full professor. Despite not having a doctorate, his promotions and eventual chairmanship of the department bore testimony to his remarkable research discoveries. He received the Hosea Ballou Medal for Distinguished Service from Tufts in 1978 and the Gold Medal of Merit from the University of Cape Town. He was a member of the National Academy of Sciences, a fellow of the American Physical Society and a member of the American Academy of Arts and Sciences. When he retired in 1980, Tufts awarded him an honorary doctorate and bestowed upon him its highest professional rank, university professor. In 1990, United States President George Bush awarded him the National Medal of Science in the physical sciences "for his scientific work including the development of computer assisted tomography; and as a scholar and teacher, especially of undergraduates".

Cormack and his wife were parents to a son, Robert, and two daughters, Margaret and Jean. He lived out his retirement years in the town of Winchester, New Hampshire, enjoying "the amenities of New England, particularly summers near, in and on Lake Winnipesaukee, New Hampshire".

Cormack died of cancer on 7 May 1998, at the age of 74, and was posthumously awarded the Order of Mapungubwe, South Africa's highest honour, in the gold category.

\section{BIBLIOGRAPHY}

- Odelberg W, ed. Autobiography of Allan M. Cormack. Les Prix Nobel. The Nobel Prizes 1979. Stockholm: Nobel Foundation, 1980

- Cherry RD. Professor RW James. South African Journal of Science 1997; 93:94-6.

- Cormack AM. Representation of a Function by Its Line Integrals, with Some Radiological Applications. J Appl Phys 1963; 34:2722.

- Cormack AM. Representation of a Function by Its Line Integrals, with Some Radiological Applications II. J Appl Phys 1964; 35:2908.

- Wikipedia. CT scan. Available at: https://en.wikipedia.org/wiki/CT_scan. Accessed December 11, 2019.

- Friedland GW, Thurber BD. The birth of CT. Am J Roentgenol 1996; 167:1365-70.

- Raju TN. The Nobel Chronicles. 1979: Allan MacLeod Cormack (b 1924); and Sir Godfrey Newbold Hounsfield (b 1919). Lancet 1999; 354:1653.

- Shampo MA, Kyle RA. Allan Cormack-codeveloper of computed tomographic scanner. Mayo Clin Pro 1996; 71:288. 